\title{
Občutek pripadnosti skupnosti in sodelovanje lastnikov pri upravljanju večstanovanjskih stavb: raziskava v Hongkongu
}

Zaradi nezadostnega sodelovanja lastnikov pri upravljanju večstanovanjskih stavb upravljanje mnogih stanovanjskih zgradb v Hongkongu ni učinkovito. Ustrezno upravljanje stanovanjskih blokov je namreč odvisno od prostovoljnih prizadevanj posameznih lastnikov. Ti pogosto izkoriščajo upravljavske napore drugih, saj koristi dobrega upravljanja stavb pojmujejo kot skupno dobro. Poleg spodbud, kot so subvencije, ki jih ponujajo državni organi, in strožji ukrepi odgovornih organov zoper lastnike, ki zanemarjajo svoje stavbe, tudi raziskovalci trdijo, da bi bile lahko pri obravnavanju problemov, povezanih z upravljanjem večstanovanjskih stavb, učinkovite tudi rešitve skupnosti. Povečuje se namreč zanimanje za uporabo socialnega kapitala, ki velja za dobrino zaupanja, vzajemnosti in sodelovanja, da bi se spodbudilo kulturo sodelovanja med lastniki, vendar primanjkuje empiričnih raziskav o tem, ali ima socialni kapital res pomembno vlogo pri upravljanju večstanovanjskih stavb. Ta raziskava preučuje povezavo med socialnim kapitalom in sodelovanjem lastnikov pri upravljanju večstanovanjskih stavb v Hongkongu. Ugotovitve te raziskave imajo pomembne posledice v praksi in stanovanjski politiki. Za trajnostno upravljanje obstoječega stavbnega fonda v Hongkongu lahko javni upravljavci poleg uporabe finančnih spodbud ali nespodbud usmerijo svoje napore $\mathrm{k}$ razvoju občutka pripadnosti skupnosti.

Ključne besede: kolektivni ukrepi, občutek pripadnosti skupnosti, upravljanje večstanovanjskih stavb, sodelovanje stanovalcev, socialni kapital 


\section{Uvod}

V 21. stoletju skoraj vse dežele in mesta po svetu v svoje programe delovanja vključujejo trajnostni razvoj. Na tem področju skrb večinoma posvečamo ekološkim in okoljskim vprašanjem, velik poudarek pa bi moral biti tudi na kakovosti bivalnega okolja. Kot predlagata Jeroen Boelhouwer (2002) in Gideon Omuta (2004), je kakovost bivanja eno najpomembnejših vprašanj, ki bi ga bilo treba obravnavati v povezavi s trajnostnim razvojem. Zlato pravilo javnih upravljavcev in upravljavcev mest je, da mora biti bivalni prostor higiensko neoporečen in varen, saj so drugače stanovalci izpostavljeni različnim varnostnim in zdravstvenim tveganjem. V kompaktnih megamestih (ang. megacities), kot so Tokio, Peking, Šanghaj in Hongkong, je tesna povezava med bivalnim okoljem in dobrim počutjem ljudi še posebej opazna. Čeprav kompaktnost teh mest zagotavlja gospodarsko učinkovitost $\mathrm{v}$ smislu skupne uporabe prostorov in komunalne infrastrukture, visoka gostota prebivalstva pogosto povzroča težave (Lynn, 1999; Vlahov in Galea, 2002). Izbruh sindroma akutne respiratorne stiske (SARS) leta 2003 je jasno pokazal, kakšne so lahko posledice slabega upravljanja stavb na gosto poseljenih mestnih območjih. Omejeno, vendar hitro širjenje te bolezni v soseskah Amoy Gardens v Hongkongu in Wen-Hua v Tajpeju je v obeh mestih povzročilo pravo zdravstveno katastrofo. Kljub temu pa se število propadajočih stavb povečuje, za pravočasno obnovo zgradb v teh megamestih pa je nujno treba okrepiti upravljanje stanovanjskih objektov in spodbuditi lastnike, da skrbijo za stavbe, $\mathrm{v}$ katerih živijo.

Težave, povezane z upravljanjem večstanovanjskih stavb, izhajajo iz medsebojne odvisnosti lastnikov stanovanj. V nasprotju s samostojnimi stanovanjskimi hišami upravljanje večstanovanjskih stavb nujno zahteva vključenost in sodelovanje lastnikov oziroma stanovalcev. Kolektivni ukrepi so za ustrezno upravljanje in vzdrževanje teh stavb namreč najpomembnejši. Klasične teorije kolektivnega ukrepanja sicer namigujejo na to, da to sodelovanje ni samodejno, še posebej če gre za veliko število lastnikov. $V$ teh primerih se morajo lastniki med seboj pogajati in dogovoriti o visokih stroških (Olson, 1965). Rešitve, ki spodbujajo kolektivne ukrepe prek uporabe določenih spodbud (na primer vladnih subvencij) ali uvedbe institucionalnih rešitev (na primer ustanavljanje združenj lastnikov stanovanj), so lahko učinkovite, vendar uporaba le takih ukrepov ni zadostna. Skupnostni pristopi (ang. communitarian approaches), kot so družbene norme in povečano vzajemno zaupanje, so pri zagotavljanju dolgotrajnejših možnosti prav tako učinkoviti. Posamezni primeri od drugod kažejo, da sta vzdrževanje in povečanje socialnega kapitala obetaven pristop k spodbujanju sodelovanja pri upravljanju in vzdrževanju stavb (Werner, 2006, 2007; Mandič, 2006). Za azijski prostor je na tem področju premalo empiričnih raziskav, zato javni upravljavci pri upravljanju stanovanjskih stavb večinoma zanemarjajo potencialno vlogo socialnega kapitala. Tako kot druge vrste kapitala (na primer človeški ali finančni kapital) je pri zagotavljanju človekovega dobrega počutja pomemben tudi socialni kapital. Ponovno se je obudilo tudi zanimanje za vlogo socialnega kapitala pri zagotavljanju kakovosti življenja ljudi (Aldridge in Halpern, 2002; Babb, 2005).

Opisana raziskava ne poskuša le nadgraditi nekaterih pomembnejših prejšnjih raziskav, ampak tudi povečati razumevanje vloge, ki jo ima občutek pripadnosti skupnosti (ang. sense of community) pri upravljanju večstanovanjskih stavb. Preučuje povezavo med občutkom pripadnosti skupnosti in sodelovanjem lastnikov pri upravljanju stavb v Hongkongu. V prispevku je najprej obravnavano vprašanje propadanja in slabega upravljanja večstanovanjskih stavb v Hongkongu, nato pa sta predstavljena pojma kolektivizem in socialni kapital. Temu sledijo predstavitev in obravnava metodologije in ugotovitev empirične raziskave, na koncu pa še sklep.

\section{Propadanje in slabo upravljanje večstanovanjskih stavb v Hongkongu}

Hongkong velja za eno najživahnejših svetovnih mest, vendar se njegovi prebivalci že dolgo soočajo s problemom propadanja stavb v mestu. Vzrok za takšno stanje lahko pripišemo pomanjkanju celovite vladne politike upravljanja in vzdrževanja stavb ter dejstvu, da lastniki ne vedo, kako za stavbe ustrezno skrbeti. Za zagotavljanje trajnostnega razvoja je treba stavbe v mestih dobro vzdrževati. Med 39.000 zasebnimi zgradbami v Hongkongu jih propada najmanj četrtina (urad za stanovanja, načrtovanje in zemljišča, 2005). Kot je prikazano v preglednici 1 , je urad za stavbe leta 2009 prejel kar trikrat več pritožb zaradi nevarnosti, povezanih s stavbami, kot leta 1995 . V poročilu delovne skupine za varnost in preventivno vzdrževanje stavb (2001) je navedeno tudi, da je med letoma 1990 in 2001 v nesrečah, povezanih s slabim vzdrževanjem stavb, umrl najmanj 101 človek, 435 ljudi pa je bilo ranjenih.

Zdravje in varnost stanovalcev in širše javnosti bosta ogrožena, če bodo stavbe v Hongkongu še naprej hitro propadale. Na primer, eden od dejavnikov, ki so prispevali k širjenju SARS na tem območju leta 2003, je bilo tudi slabo vzdrževanje odtočnih sistemov v stavbah. Varnostne težave, povezane z mestnimi stanovanjskimi zgradbami, po navadi vključujejo poslabšanje konstrukcijskih značilnosti stavb, slabo zagotavljanje požarne varnosti in širjenje nedovoljenih gradbenih posegov. Zaradi visoke vsebnosti klorida v betonu, ki se uporablja pri gradnji, je armirani beton v mnogih stavbah, zgrajenih med leti 1959 in 1965 ter 1971 in 1975, razpadel veliko prej kot v predvideni petdesetletni dobi delovanja (Leung in Yiu, 2004). Urad za 
Preglednica 1: Podatki o prijavah nevarnosti v zvezi s stavbami, ki jih je prejel urad za stavbe

\begin{tabular}{llllll}
\hline Leto & $\begin{array}{l}\text { Nevarne oglasne } \\
\text { površine }\end{array}$ & Nevarne stavbe & Nevarna pobočja & $\begin{array}{l}\text { Nedovoljeni gradbeni } \\
\text { posegi }\end{array}$ & Skupno število prijav \\
\hline 1995 & 230 & 1.974 & 38 & 8.203 & 10.445 \\
\hline 1996 & 165 & 2.567 & 91 & 9.913 & 12.736 \\
\hline 1997 & 350 & 3.658 & 130 & 12.427 & 16.915 \\
\hline 1998 & 250 & 3.851 & 53 & 12.577 & 16.731 \\
\hline 1999 & 614 & 4.730 & 130 & 16.999 & 22.473 \\
\hline 2000 & 260 & 4.280 & 71 & 13.911 & 18.522 \\
\hline 2001 & 178 & 6.671 & 41 & 12.764 & 19.654 \\
\hline 2002 & 135 & 5.956 & 52 & 21.844 & 27.987 \\
\hline 2003 & 181 & 8.665 & 48 & 24.870 & 33.764 \\
\hline 2004 & 303 & 10.407 & 146 & 21.123 & 42.069 \\
\hline 2006 & 331 & 13.999 & 208 & 25.683 & 32.366 \\
\hline 2007 & 564 & 6.758 & 183 & 24.861 & 29.649 \\
\hline 2008 & 322 & 4.566 & 128 & 24.633 & 31.230 \\
\hline 2009 & 563 & 4.412 & 313 & 24.942 & 31.365 \\
\hline
\end{tabular}

Vir: urad za stavbe $(1999,2003,2008,2010)$

stavbe (1999) poroča, da so neučinkovita popravila propadanje stavb še poslabšala. Ne samo da razpadanje betona močno oslabi stabilnost konstrukcije stavbe, ampak lahko kosi betona, ki padajo s pročelja, tudi ubijejo mimoidoče (delovna skupina za varnost in preventivno vzdrževanje stavb, 2001).

Kot je razvidno iz preglednice 1, nedovoljeni gradbeni posegi prevladujejo na seznamu nevarnosti, povezanih s slabim vzdrževanjem stavb, ki so bile prijavljene uradu za stavbe. Nedovoljen gradbeni poseg je poseg, ki se izvede brez predhodnega dovoljenja in soglasja pristojnega organa (Yiu, 2005; Yiu in Yau, 2005). Nedovoljeni gradbeni posegi ogrožajo varnost, saj načrtov in izvedbe niso pregledali pristojni organi. Povedano drugače, za brezhibno stanje in kakovost uporabljenih materialov ni mogoče jamčiti. Nedovoljeni gradbeni posegi poslabšajo stabilnost konstrukcije in požarno varnost stavb (Lai in Ho, 2001). Urad za stavbe (2007) je ocenil, da je bilo v Hongkongu izvedenih približno 750.000 nedovoljenih gradbenih posegov in da so ti posegi med letoma 1990 in 2002 povzročili najmanj 21 smrtnih žrtev in 135 poškod (Leung in Yiu, 2004). Vzroke za širjenje nedovoljenih gradbenih posegov je mogoče pripisati pomanjkanju zazidljivih zemljišč (Lai, 2003), slabemu upravljanju stavb (Lai in Ho, 2001), visokim stroškom postopkov zoper kršitve (Yiu, 2005) in nejasni zakonodaji (Yiu in Yau, 2005). V zvezi s požarno varnostjo pa je to vprašanje po številnih tragičnih požarih konec devetdesetih let prejšnjega stoletja vzbudilo veliko skrb javnosti (Walters in Hastings, 1998). Leta 2008 je bilo v hongkonških stanovanjskih zgradbah zabeleženih 3.299 požarov, kar pomeni, da je bilo vsak dan v povprečju zabeleženih devet primerov (požarna služba, 2009). Med večje pomanjkljivosti in nepravilnosti pri požarni varnosti stavb spadajo ovirani zasilni izhodi, okvarjene ali slabo vzdrževane gasilne naprave, nevarna električna napeljava v skupnih prostorih in neustrezna uporaba stavbe (urad za varnost in urad za notranje zadeve, 1998). V večini primerov nastanejo težave zaradi pomanjkanja ustreznega upravljanja na področju požarne varnosti in nevzdrževanja gasilnih naprav. Poleg težav $\mathrm{z}$ varnostjo konstrukcije stavb in s požarno varnostjo vznemirjajo prebivalce Hongkonga tudi materiali, ki odpadajo s stavb. Nesreče s smrtnim izidom zaradi odpadajočih materialov, kot so aluminijasta okna in kosi betona, so zadnja leta pogoste (Bowring, 2005; urad za informiranje, 2005; Lo, 2005; urad za stavbe, 2007).

\section{Kolektivizem pri upravljanju stanovanj}

Ob ustreznem načrtovanju in gradnji so nove stavbe običajno varne. Kljub temu pa so tako kot druge fizične dobrine izpostavljene obrabi, zaradi česar se lahko raven njihove uporabnosti po določenem času zmanjša. Vzdrževanje in popravila so nujno potrebni za to, da stavbo obvarujemo pred trajnim propadanjem (Choy, 1998). Zaradi solastništva večine večnadstropnih stanovanjskih zgradb v Hongkongu pa so ta izboljševalna dela pogosto ovirana, zlasti v skupnih prostorih, kot so preddverja, hodniki, stopnišča in dvigala. V sistemu solastništva imajo posamezni lastniki stanovanj izključno pravico uporabe svojih stanovanjskih enot, poleg tega pa lahko uporabljajo tudi skupne prostore (Nield, 1990). Vsi lastniki skupno odgovarjajo za vzdrževanje skupnih prostorov, kar pomeni, da morajo pri upravljanju in vzdrževanju stavbe med seboj sodelovati in se usklajevati (Bailey in Robertson, 1997; Chen in Webster, 2005). 


\subsection{Kolektivni ukrepi in izkoriščanje naporov drugih pri upravljanju večstanovanjskih stavb}

Obstaja kar nekaj dokazov in posameznih primerov, iz katerih je razvidno, da sodelovanje stanovalcev neposredno in pozitivno vpliva na upravljanje večstanovanjskih stavb in zadovoljstvo stanovalcev (glej Cairncross idr., 1997, ali urad za javno upravljanje, 1999). Vendar pa prizadevanja za kolektivno sodelovanje stanovalcev pri upravljanju stavb običajno niso uspešna (Bengtsson, 1998). Pri pridobivanju soglasja preostalih lastnikov za določena nujna in pomembna vzdrževalna dela se lahko posamezni lastniki soočajo s težavami (Yip in Forrest, 2002). Pri pogajanju, usklajevanju in reševanju sporov pogosto nastanejo visoki stroški za to, da se med posameznimi lastniki doseže skupni dogovor, ki pripomore $\mathrm{k}$ izboljšavam na stavbi. To pa pogosto vodi $\mathrm{k}$ nezadostnemu vlaganju $\mathrm{v}$ vzdrževanje stavbe. Upravljanje zasebnih večstanovanjskih stavb, zlasti tistih v etažni lastnini ali z več lastniki, je po naravi skupno. Rezultati dobrega upravljanja večstanovanjskih stavb (na primer čisti in higiensko neoporečni prostori, varnost in povečano varovanje) so javne dobrine, vendar obenem niso izključne. $\mathrm{Na}$ primer, lastnik $A$, ki plača določeno javno dobrino, lastniku $B$ ne more preprečiti uživanje te dobrine. Na podlagi te opredelitve upravljanja večstanovanjskih stavb je Bo Bengtsson (2001) razvil zamisel, da se z vidika teorije iger (ang. game theory) racionalnim lastnikom bolj izplača, če med seboj ne sodelujejo, saj s tem povečajo svoj dobitek. Drugače povedano, to načelo ali sebičnost lahko lastnike napelje $\mathrm{k}$ temu, da pri upravljanju stavbe izkoriščajo napore drugih (ang. free ride).

Jasno je, da kolektivni ukrepi niso samoumevni, še posebej če gre za veliko število lastnikov (Olson, 1965). Ko se morajo lastniki enostransko odločiti, ali bodo pomagali zagotoviti določeno skupno dobrino, se jih glede na trenutno stanje večina obnaša oportunistično in izkorišča napore drugih (Walters in Kent, 2000; Lai in Chan, 2004). Kolektivno ukrepanje zahteva določene spodbude (na primer nagrade in kazni za posameznike), ki bi stanovalce spodbudile k sodelovanju (Olson, 1965). Kljub temu to vodi le $\mathrm{k}$ zanemarljivim in nestalnim rešitvam problema izkoriščanja drugih (Bengtsson, 1998). Institucionalne rešitve, ki urejajo vedenje ljudi $s$ formalnimi pravili ali z neformalnimi omejitvami za zmanjšanje negotovosti (Walters, 2002), najpogosteje »zagotavljajo le minimalno raven kolektivnega ukrepanja « (Bengtsson, 1998: 118). Ker je treba institucionalne rešitve še ustrezno organizirati, legitimna izhodišča za kolektivno ukrepanje pa so redka, je velika pozornost namenjena gospodarskim in pravnim sredstvom za reševanje problemov, povezanih s slabim upravljanjem stavb. V nekaterih primerih so se zakoni in predpisi izkazali za neučinkovite (Ellickson, 1991), stroški institucionalne rešitve pa so preprosto previsoki, če želimo pri lastnikih spodbuditi konstruktivne kolektivne ukrepe (Walter, 2002). Večina raziskav posredno domneva, da je ekonomsko načelo osnovni motivator kolektivnega ukrepanja, in zavrača misel, da so lahko družbene norme osnova za racionalne odločitve (Elster, 1989). Empirične študije primerov so pokazale, da lahko »dolgoročni sosedski odnosi, vsakdanji osebni stiki v lokalnem stanovanjskem okolju in omejena velikost skupine pomagajo spodbuditi sodelovanje [med stanovalci] « (Bengtsson, 1998: 114). To pomeni, da lahko skupnostni pristop ponudi obetavno rešitev problema skupnega ukrepanja.

\subsection{Skupnostni pristop $\mathrm{k}$ reševanju problema upravljanja stanovanj}

Za uspešnost skupnostnega pristopa je bistveno, da ima večina lastnikov (če ne že vsi) enake vrednote glede upravljanja stavbe. Upravljanje skupnih prostorov in komunalne opreme $\mathrm{v}$ večstanovanjskih stavbah zahteva, da lastniki na stvari pogledajo širše in tako vidijo, kaj se zares dogaja v njihovi stavbi ali soseski. Socialni kapital ima pri tem pomembno vlogo. V skladu s prvo sistematično konceptualizacijo socialnega kapitala, ki jo je razvil Pierre Bourdieu, je socialni kapital ena od štirih oblik kapitala (to je ekonomskega, socialnega, kulturnega in simbolnega). Bourdieu (1985: 248) je socialni kapital opredelil kot »skupek dejanskih ali potencialnih virov, povezanih $s$ posedovanjem trajne mreže bolj ali manj institucionaliziranih odnosov vzajemnega poznanstva «. Socialni kapital lahko razumemo kot zaupanje v svoje sosede in skrb zanje ter pripravljenost živeti v skladu z normami svoje skupnosti in kaznovati tiste, ki se tega ne držijo (Putnam, 2000; Rothstein, 2005). Pri kolektivnem ukrepanju je socialni kapital ključ do oblikovanja rešitev skupnosti. Elinor Ostrom (1990) je trdila, da lahko socialni kapital poveča verjetnost pripravljenosti za sodelovanje pri zapornikovih dilemah, zasebnem zagotavljanju javnih dobrin in upravljanju virov skupnega premoženja. Poleg tega lahko socialni kapital pomaga tudi znižati stroške sodelovanja, saj ljudem vliva dovolj zaupanja, da vlagajo v skupne dejavnosti in pri njih sodelujejo, ker vedo, da drugi počnejo isto (Bengtsson, 1998).

Povezave med socialnim kapitalom in urbanim upravljanjem so že dolgo predmet raziskav. Margit Mayer (2003) je preučevala vlogo socialnega kapitala pri urbanih družbenih gibanjih. David Chavis in Abraham Wandersman (1990) sta ugotovila, da občutek pripadnosti skupnosti deluje kot katalizator pri spodbujanju prostovoljnih ukrepov, kot je sodelovanje v združenju lastnikov stanovanj v bloku. Steven Hornburg in Robert Lang (1997) sta predlagala, da je treba pri oblikovanju stanovanjske politike natančno preučiti socialni kapital. $V$ povezavi z upravljanjem večstanovanjskih stavb Josh Weston (2001) trdi, da kakovosti stanovanjskih zgradb ni mogoče ohranjati le $s$ 
skrbnim vzdrževanjem. Skupnostni pristop, ki temelji na socialnem kapitalu ali občutku pripadnosti skupnosti, pa spodbuja ponos in odgovornost ter pomaga krepiti norme in odnose med stanovalci. Zato je tudi koristnejši za oblikovanje trajnostnega režima kakovostnih stanovanj. Podobno Srna Mandič (2006) ugotavlja, da ima socialni kapital poleg pričakovanih dejavnikov, kot sta fizično stanje zgradb in finančni položaj lastnikov, odločilno vlogo pri tem, ali so večstanovanjske stavbe prenovljene pravočasno. Inga-Britt Werner $(2006,2007)$ zagovarja uporabo socialnega kapitala kot analitičnega orodja za oblikovanje učinkovitih ciljev pri načrtovanju upravljanja in vzdrževanja, ki bi jih podjetja, ki se ukvarjajo z upravljanjem večstanovanjskih stavb, morala sprejeti kot pomemben del svojih dejavnosti. Kot to poudarjata Susan Saegert in Gary Winkel (1998), je bil socialni kapital tesno povezan s fizičnim stanjem lokalno sponzoriranih socialnih stanovanj v Združenih državah Amerike. V večini primerov naj bi socialni kapital pozitivno vplival na upravljanje večstanovanjskih stavb, vendar so $\mathrm{v}$ našem teoretičnem in empiričnem razumevanju tega pojava še vedno vrzeli. Zato je namen te raziskave preučiti vplive socialnega kapitala na upravljanje večstanovanjskih stavb v Hongkongu.

\section{Metodologija in uporabljeni podatki}

V raziskavo smo vključili stanovalce dveh podobnih stanovanjskih blokov, da bi preučili vplive socialnega kapitala na upravljanje večstanovanjskih stavb.

\subsection{Zasnova raziskave}

Izvedli smo anketo po gospodinjstvih, pri kateri smo uporabili strukturiran vprašalnik. Ker je socialni kapital abstrakten pojem, ga je težko opredeliti (Coleman, 1988), poleg tega je treba operacionalizirati njegovo merjenje. Julie Ann Pooley idr. (2005) trdijo, da sta socialni kapital in občutek pripadnosti skupnosti podobna pojma oziroma da se prekrivata, zato smo socialni kapital v tej raziskavi merili kot občutek pripadnosti skupnosti, ki smo ga nato ocenili s pomočjo kratkega indeksa občutka pripadnosti skupnosti (ang. Brief Sense of Community Index, v nadaljevanju: BSCI), ki sta ga razvila D. Adam Long in Douglas Perkins (2003). V BSCI temelji občutek pripadnosti na družabnih vezeh, skupnih interesih in skupnih vrednotah. $\mathrm{V}$ preglednici 2 je predstavljenih vseh osem vprašanj, ki smo jih $\mathrm{v}$ zvezi s temi dejavniki postavili anketirancem. Ti so nanje odgovarjali s pomočjo petstopenjske Likertove lestvice, pri čemer je vrednost 5 pomenila, da se s trditvijo popolnoma strinjajo, vrednost 1 pa, da se s trditvijo sploh ne strinjajo. Poleg vprašanj, $s$ katerimi smo želeli ugotoviti občutek pripadnosti skupnosti, smo vključili tudi vprašanja o tem, kaj anketiranci menijo o kakovosti stavbe in svojem sodelovanju pri njenem upravljanju.

Preglednica 2: Vprašanja o občutku pripadnosti skupnosti, kot ga dojemajo anketiranci.

\begin{tabular}{|c|c|}
\hline Dejavnik & Se strinjate $z$ naslednjimi trditvami? \\
\hline \multirow{3}{*}{ družabne vezi } & 1. Poznam večino ljudi v svoji stavbi. \\
\hline & 2. Večina sosedov me pozna. \\
\hline & $\begin{array}{l}\text { 3. Lahko vplivam na to, kakšen je videz } \\
\text { stavbe. }\end{array}$ \\
\hline \multirow{3}{*}{ skupni interesi } & $\begin{array}{l}\text { 4. S sosedi se strinjamo glede potreb stav- } \\
\text { be. }\end{array}$ \\
\hline & $\begin{array}{l}\text { 5. Če je v stavbi težava, jo lahko stanovalci } \\
\text { rešimo. }\end{array}$ \\
\hline & $\begin{array}{l}\text { Na splošno ljudje v moji stavbi skrbijo } \\
\text { 6. drug za drugega in si pomagajo, če le } \\
\text { lahko. }\end{array}$ \\
\hline \multirow{2}{*}{ skupne vrednote } & $\begin{array}{l}\text { 7. Zame je zelo pomembno, da občutim } \\
\text { pripadnost z ljudmi v stavbi. }\end{array}$ \\
\hline & $\begin{array}{l}\text { 8. } V \text { stavbi občutim močno pripadnost } \\
\text { skupnosti. }\end{array}$ \\
\hline
\end{tabular}

Vir: prirejeno po Long in Perkins (2003)

\subsection{Opis stavb, vključenih v raziskavo}

V Sai Wanu, zahodnem okrožju Hongkonga, smo izbrali dve enajstnadstropni stavbi. Stavba A s 55 gospodinjstvi je bila zgrajena leta 1965, stavba B z 58 gospodinjstvi pa leta 1964. Obe sta imeli dvigalo in podobne lastnosti (na primer obseg

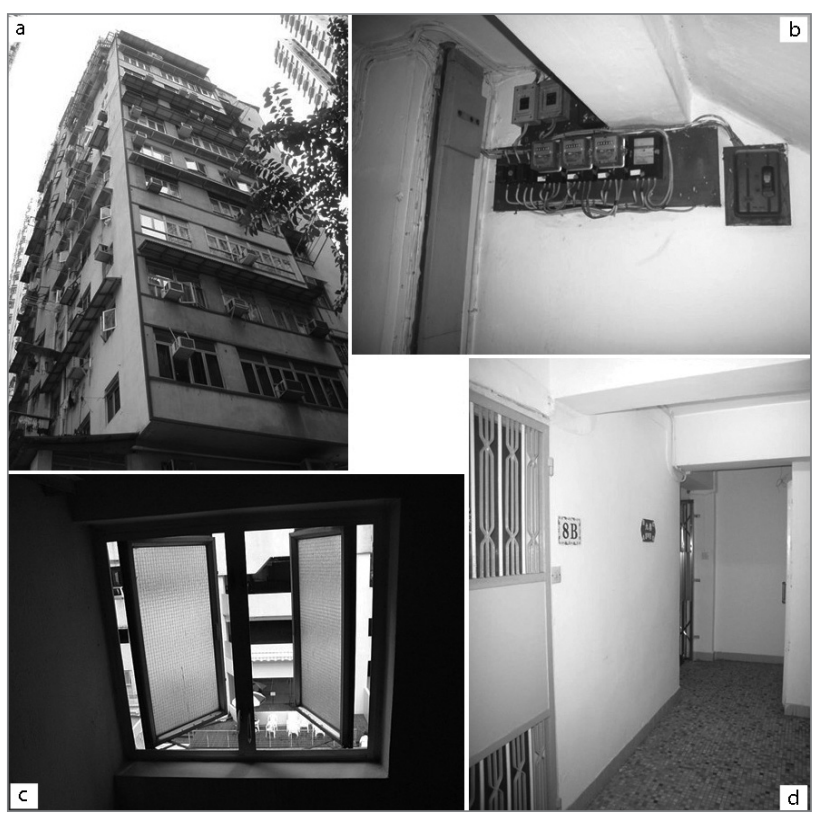

Slika 1: Fizične in higienske razmere v stavbi $A$; (a) pročelje, (b) električni števec in notranji priključek, (c) stopniščno okno v dobrem stanju, (d) skupni hodnik (foto: Yung Yau). 
gradnje in starost). Demografske razlike smo zmanjšali tako, da smo izbrali stavbi iz istega okoliša. Stavbi ni upravljalo zunanje podjetje za upravljanje nepremičnin, saj sta probleme, povezane z upravljanjem stavb, reševali kar združbi lastnikov (ang. owners' corporations, v nadaljevanju: OC) obeh stavb. Na podlagi ogleda obeh stavb smo ugotovili, da je bila stavba A bolje upravljana kot stavba B. Kot je razvidno s slike 1, so bili v stavbi A materiali in komunalna oprema bolje vzdrževani, prostori pa so bili čisti in higiensko neoporečni. Kot je razvidno tudi s slike 2, smo v stavbi B opazili poškodbe v stavbni opremi in materialih (na primer krušenje zidu in počeno okensko steklo) ter neurejene skupne prostore (na primer razni predmeti pod stopniščem).

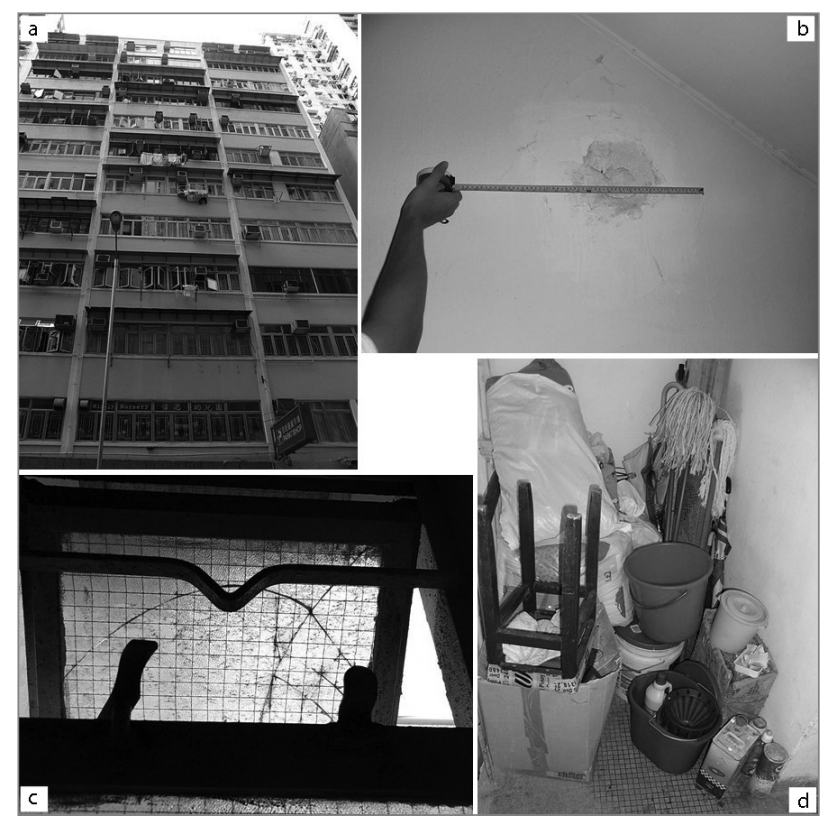

Slika 2: Fizične in higienske razmere v stavbi B; (a) pročelje, (b) krušenje zidu na stopnišču, (c) počeno steklo v stopniščnem oknu, (d) razni predmeti pod stopniščem (foto: Yung Yau).

\subsection{Opisi anketirancev}

Anketa v gospodinjstvih je potekala od februarja do marca 2009. Ker smo za ciljno skupino izbrali lastnike stanovanj (oziroma lastnike, ki so tam tudi stanovali), smo anketo prekinili, če smo ugotovili, da je anketiranec podnajemnik. Skupno smo $s$ pomočjo vnaprej pripravljenega vprašalnika anketirali trideset lastnikov (petnajst v vsaki stavbi, kar je med 26 in $27 \%$ vseh lastnikov v obeh stavbah). Anketiranci so v teh stavbah prebivali povprečno 23,5 leta. Druge lastnosti anketirancev so predstavljene v preglednici 3 . Na splošno med anketiranci v obeh stavbah ni bilo velikih razlik. Štirje anketiranci v stavbi A in pet anketirancev $v$ stavbi B je bilo članov odborov posamezne OC.
Preglednica 3: Opisi anketirancev v obeh stavbah (\%)

\begin{tabular}{|c|c|c|c|}
\hline Lastnosti & $\begin{array}{l}\text { Celoten } \\
\text { vzorec }\end{array}$ & Stavba A & Stavba B \\
\hline \multicolumn{4}{|l|}{ spol } \\
\hline moški & 56,7 & 60,0 & 53,3 \\
\hline ženski & 43,3 & 40,0 & 46,7 \\
\hline \multicolumn{4}{|l|}{ starost } \\
\hline 18-24 let & 6,7 & 6,7 & 6,7 \\
\hline 25-34 let & 16,7 & 20,0 & 13,3 \\
\hline 35-44 let & 36,7 & 33,3 & 40,0 \\
\hline 45-54 let & 30,0 & 33,3 & 26,7 \\
\hline 55 let ali več & 10,0 & 6,7 & 13,3 \\
\hline \multicolumn{4}{|l|}{ izobrazba } \\
\hline osnovna šola ali manj & 6,7 & 6,7 & 6,7 \\
\hline srednja šola & 23,3 & 26,7 & 20,0 \\
\hline višja šola & 36,7 & 33,3 & 40,0 \\
\hline $\begin{array}{l}\text { univerzitetna diploma } \\
\text { ali več }\end{array}$ & 33,3 & 33,3 & 33,3 \\
\hline \multicolumn{4}{|l|}{ dohodek gospodinjstva } \\
\hline 9.999 HK\$ ali manj & 0,0 & 0,0 & 0,0 \\
\hline 10.000-14.999 HK\$ & 13,3 & 13,3 & 13,3 \\
\hline 15.000-19.999 HK\$ & 20,0 & 20,0 & 20,0 \\
\hline 20.000-24.999 HK\$ & 30,0 & 26,7 & 33,3 \\
\hline 25.000-29.999 HK\$ & 26,7 & 26,7 & 26,7 \\
\hline 30.000 HK\$̦ ali več & 10,0 & 13,3 & 6,7 \\
\hline \multicolumn{4}{|l|}{ poklic } \\
\hline visoki in srednji kader & 13,3 & 6,7 & 20,0 \\
\hline $\begin{array}{l}\text { uradniki in storitveni } \\
\text { delavci }\end{array}$ & 23,3 & 26,7 & 20,0 \\
\hline delavci v proizvodnji & 3,3 & 0,0 & 6,7 \\
\hline študenti & 13,3 & 20,0 & 6,7 \\
\hline gospodinje & 16,7 & 13,3 & 20,0 \\
\hline upokojenci & 10,0 & 6,7 & 13,3 \\
\hline drugo & 3,3 & 6,7 & 0,0 \\
\hline brezposelni & 16,7 & 20,0 & 13,3 \\
\hline
\end{tabular}

\section{Ugotovitve in razprava}

Ugotovitve ankete, ki smo jo izvedli v gospodinjstvih, so predstavljene v preglednici 4 . Anketiranci so zaznali višjo kakovost $\mathrm{v}$ stavbi A (povprečna ocena $=3,65$ ) kot v stavbi B (povprečna ocena $=2,69)$. Razlika je bila statistično značilna $(p<0,01)$ Ta rezultat kaže, da se subjektivne zaznave anketirancev glede kakovosti stavb bolj ali manj ujemajo z avtorjevimi začetnimi ugotovitvami. Zato veliko raziskav (glej Galster in Hesser, 1981, ter Liu, 1999) namesto kakovosti stavb ali stanovanj uporablja oziroma ugotavlja zadovoljstvo stanovalcev. V drugih raziskavah (glej Elsinga in Hoekstra, 2005, ter Ha in Weber, 2009) so avtorji prav tako ugotovili, da obstaja povezava med kakovostjo stanovanja in zadovoljstvom stanovalcev. 


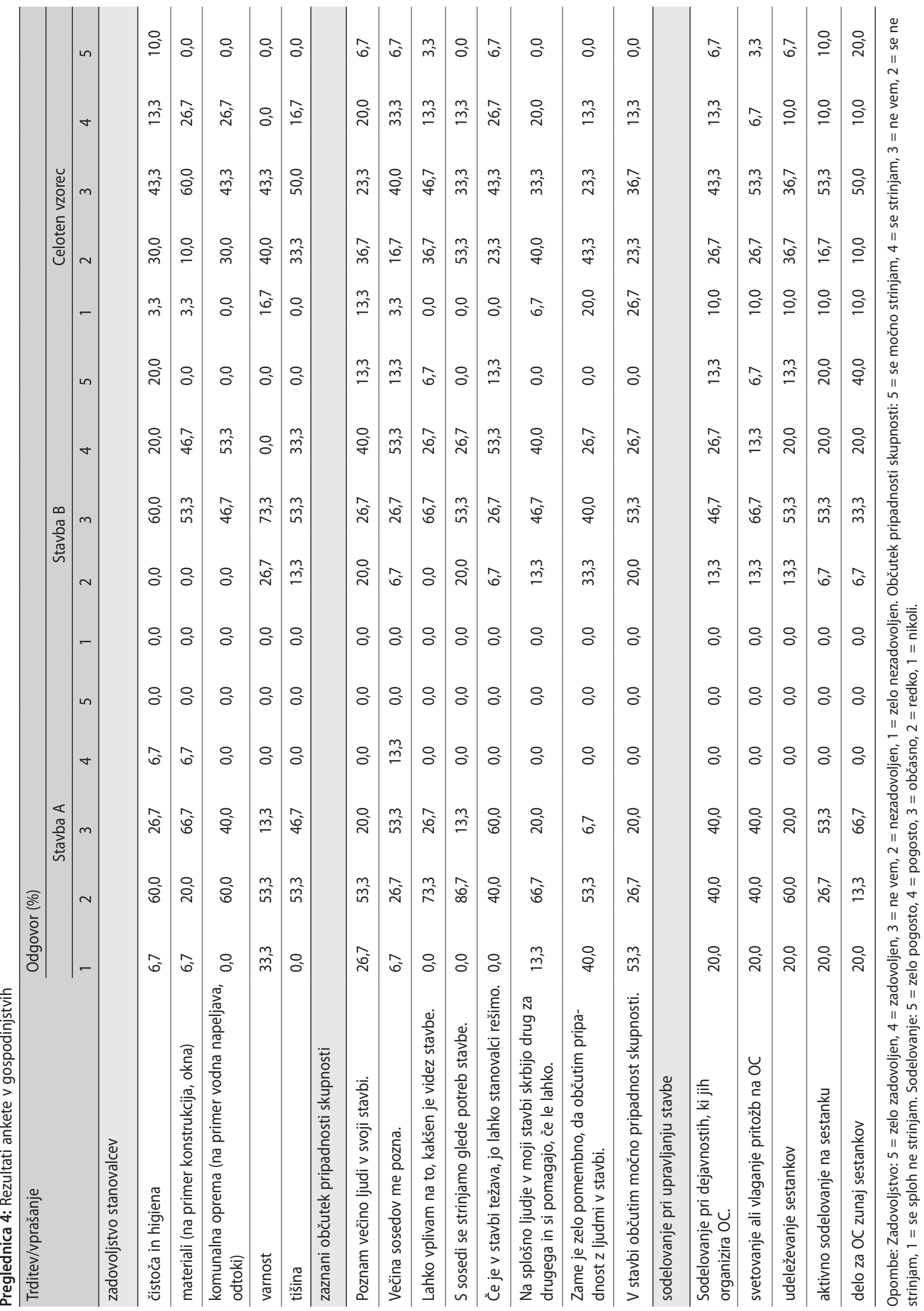


$\mathrm{V}$ primerjavi s stavbo $\mathrm{B}$ (povprečna ocena $=2,67$ ) je bil rezultat BSCI za stavbo A višji (povprečna ocena $=3,87$ ), razlika pa je bila ponovno statistično značilna pri vrednosti $p<0,01$. Pri treh dejavnikih (to je družabnih vezeh, skupnih interesih in skupnih vrednotah) so bile razlike največje pri skupnih vrednotah. Vzrok za to je mogoče pripisati temu, da se anketirancem $\mathrm{v}$ stavbi B občutek pripadnosti skupnosti ni zdel tako pomemben za njihovo dobro počutje in so ga zato ocenili nizko. $\mathrm{Na}$ tem mestu je že jasno, da obstajajo pozitivne povezave med občutkom pripadnosti skupnosti, dejanskim stanjem stavb in zadovoljstvom stanovalcev s stavbo. Boljše stanje in večje zadovoljstvo stanovalcev stavbe A lahko pripišemo dejavnejšemu sodelovanju lastnikov pri reševanju problemov, povezanih z upravljanjem stavbe. $Z$ večjo stopnjo sodelovanja stanovalcev se lahko težave, povezano $s$ stavbo, učinkoviteje rešijo. Iz rezultatov ankete je razvidno, da je bila povprečna pogostnost sodelovanja anketirancev v stavbi A (povprečna ocena $=3,92$ ) bistveno višja $(1 \%)$ kot v stavbi $B$ (povprečna ocena $=2,70)$. Ti rezultati nakazujejo pozitivno povezavo med občutkom pripadnosti skupnosti in sodelovanjem lastnikov pri upravljanju stavbe. Ugotovitve do neke mere potrjujejo dognanja Abrahama Wandersmana in Garyja Giamartina (1980), ki sta ugotovila, da je občutek pripadnosti skupnosti pomembno vplival na sodelovanje na sestankih organizacije stanovalcev določene ulice (ang. block organisation) v Združenih državah Amerike.

Kolektivizem je bistvenega pomena za ustrezno upravljanje in vzdrževanje večnadstropnih stanovanjskih zgradb v Hongkongu, zato bi se sodelovanje lastnikov stanovanj moralo spodbujati. Iz ugotovitev te raziskave je razvidno, da je občutek pripadnosti skupnosti pomemben za sodelovanje lastnikov pri upravljanju večstanovanjskih stavb v mestu. Povedano drugače, učinkovito upravljanje večstanovanjskih stavb lahko dosežemo $s$ skupnostnim pristopom. Ne glede na to, ali gre za prisilo ali gospodarske spodbude, se lahko lastniki stanovanj odločijo, da pri upravljanju stavb ne bodo sodelovali, ker mislijo, da bodo drugi lastniki izkoriščali njihove napore (Bengtsson, 1998). Tako nezaupanje pripelje do tega, da skupne dobrine, ki ustvarjajo zdravo, varno in prijetno bivalno okolje, niso zagotovljene. Občutek pripadnosti skupnosti v stanovanjkkih zgradbah je zato treba spodbujati, na primer z organiziranjem družabnih dejavnosti (na primer izletov in spomladanskih pogostitev) oziroma sodelovanjem pri različnih tekmovanjih v stavbi ali stanovanjskem naselju (na primer tekmovanja v čistoči stavbe ali recikliranju odpadkov). S sodelovanjem pri teh družabnih dejavnostih in dogodkih lahko lastniki bolje spoznajo svoje sosede in razvijejo vrednote, ki so skupne celi skupnosti. Postopoma bodo lastniki začeli pogosteje sodelovati pri reševanju problemov upravljanja stavb. Uprava Hongkonga bi morala ta skupnostni pristop uporabiti za reševanje trenutnih težav, povezanih s pomanjkanjem sodelovanja pri upravljanju večstanovanjskih stavb. Vladne in nevladne organizacije lahko orga- nizirajo ali sponzorirajo družabne dejavnosti in prireditve in tako v različnih lokalnih skupnostih pomagajo razviti občutek pripadnosti skupnosti.

Poleg tega lahko sodelovanje pri upravljanju večstanovanjskih stavb spodbujamo tudi s prilagajanjem strukture stavb in stanovanjskih naselij. Oblika bivalnega okolja pomembno vpliva na dobro počutje stanovalcev v družbi. Ash Amin (2002) na primer trdi, da lahko oblikovanje javnega skupnega prostora pripelje do razvoja ali okrepitve družabnih odnosov med stanovalci lokalne skupnosti. Zahteve po zagotovitvi in oblikovanju takega skupnega prostora $\mathrm{v}$ zasebnih stanovanjskih zgradbah ali stanovanjskih naseljih pa do zdaj še niso postale sestavni del stavbnih predpisov v Hongkongu. Lokalna uprava bi morala spremeniti zakone, v skladu s katerimi bi pri gradnji novih stanovanj investitorji morali zagotoviti minimalen obseg skupnih prostorov. Skupni prostori so lahko različnih oblik (na primer klubi, parki in družabni prostori). Splošno gledano zahteve po zagotavljanju skupnega prostora ne bi smele veljati le za gradnjo stavb, ampak bi moralo vsako okrožje imeti skupne prostore ali javni odprti prostor z natančno določenim minimalnim obsegom. Zato bi bilo morda treba popraviti tudi urbanistične standarde v Hongkongu.

Glede na tesno povezavo med občutkom pripadnosti skupnosti in sodelovanjem lastnikov pri upravljanju večstanovanjskih stavb bi se morali osredotočiti na ohranjanje socialnega kapitala in ne le na spodbujanje družabnih vezi v stanovanjskem naselju. Spori med lastniki so v Hongkongu pogosti, običajno pa nastanejo zaradi okvare (na primer puščanje vode), ki prizadene dve stanovanji ali več. Alternativno reševanje sporov v Hongkongu ni priljubljeno, zato se sprte stranke najpogosteje zanašajo na neprijazna pogajanja ali tožbe. Tako se odnosi med vpletenimi strankami poslabšajo, kar negativno vpliva na razvoj občutka pripadnosti skupnosti med lastniki. Na področju upravljanja večstanovanjskih stavb bi bilo bolje uporabljati metode sporazumnega in neprovokativnega reševanja sporov, kot sta sodna presoja (adjudikacija) in mediacija.

\section{Sklep}

Pretekle raziskave so pokazale, da ima upravljanje stanovanjskih zgradb, ki imajo več lastnikov, lastnosti javne dobrine (to je izpostavljeno je problemu izkoriščanja naporov drugih). Upoštevanje načela racionalnosti pogosto vodi $\mathrm{k}$ nesodelovanju pri upravljanju večstanovanjskih stavb, nekateri raziskovalci pa trdijo, da bi ljudje lahko bolje sodelovali z uporabo skupnostnega pristopa. Namen te raziskave ni kriviti lastnike stanovanj za njihovo nedejavnost pri reševanju problemov, povezanih z upravljanjem stavb. Naš cilj je bila analiza vzgibov za sodelovanje lastnikov pri upravljanju večstanovanjskih stavb in z njo ugotoviti, kako bi lahko dosegli bolǰse upravljavske rezultate 
v zasebnih večstanovanjskih stavbah v Hongkongu. To se ujema z Bengtssonovim (1998) predlogom, da je treba preučevati uspešne primere kolektivnega ukrepanja, ne pa neuspešnih. $S$ pomočjo ankete, izpeljane $\mathrm{v}$ gospodinjstvih dveh stanovanjskih zgradb v Hongkongu, smo ugotovili, da je občutek pripadnosti skupnosti povezan $s$ stopnjo sodelovanja stanovalcev pri upravljanju večstanovanjskih stavb in s kakovostjo bivalnega okolja.

Cilj raziskave ni bilo zmanjšanje pomena kazenskih zakonov in ekonomskih spodbud, ki ljudi spodbujajo k skrbi za svojo lastnino. Vendar lahko na podlagi empiričnih dognanj ugotovimo, kako najbolje pristopiti k problemu slabega upravljanja stavb. Če je uprava Hongkonga odločena rešiti problem propadanja stavb in spodbuditi lastnike, da skrbijo za stavbe, v katerih živijo, bi morala vložiti svoje napore v spodbujanje skupnostnega pristopa (na primer krepitev občutka pripadnosti skupnosti). To lahko dosežemo na več načinov. Prvič, vladne ali nevladne organizacije lahko organizirajo ali sponzorirajo družabne dejavnosti, ki stanovalcem omogočajo, da drug drugega bolje spoznajo. Drugič, oblikovanje javnega skupnega prostora bi vodilo $\mathrm{k}$ vzpostavljanju in krepitvi družabnih odnosov, pri čemer bi morala uprava zahtevati, da se pri gradnji novih stanovanj upošteva minimalen obseg skupnih prostorov. Poleg tega bi bilo treba pri načrtovanju mest upoštevati tudi oblikovanje javnih odprtih prostorov. Tretjič, družabne vezi se rahljajo zaradi neustreznega reševanja sosedskih sporov. Brez prijateljskih metod reševanja konfliktov se odnosi med vpletenimi strankami porušijo, zato bi morala mestna uprava zagotoviti nova izhodišča za sporazumno reševanje sporov.

\section{Yung Yau}

City University of Hong Kong, Department of Public and Social

Administration, Kowloon, Hongkong

E-pošta:y.yau@cityu.edu.hk

\section{Zahvala}

Raziskava je bila financirana s pomočjo raziskovalne štipendije, ki jo je odobrila mestna univerza v Hongkongu (št. projekta: 7200123). Avtor se za pomoč pri zbiranju podatkov zahvaljuje tudi študentom mestne univerze v Hongkongu.

\section{Viri in literatura}

Aldridge, S. in Halpern, D. (2002): Social capital: A discussion paper. London, Cabinet Office.

Amin, A. (2002): Ethnicity and the multicultural city: living with diversity. Environment and Planning A, 34(6), str. 959-980.

Badd, P. (2005): Measurement of social capital in the UK. London, Office for National Statistics.

Bailey, N., in Robertson, D. (1997): Management of flats in multiple ownership: Learning from other countries. Bristol, Policy Press.
Bengtsson, B. (1998): Tenants' dilemma: On collective action in housing. Housing Studies, 13(1), str. 99-120.

Bengtsson, B. (2001): Solving the tenants' dilemma: Collective action and norms of co-operation in housing. Housing, Theory and Society, 17(4), str. 175-187.

Boelhouwer, J. (2002): Social indicators and living conditions in the Netherlands. Social Indicators Research, 60(1), str. 89-113.

Bourdieu, P. (1985): The forms of capital. V: Richardson, J. G. (ur.): Handbook of theory and research for the sociology of education, str. 241-258. New York, Greenwood.

Cairncross, E., Clapham, D., in Goodlad, R. (1997): Housing management, consumers and citizens. London, Routledge.

Chavis, D. M., in Wandersman, A. (1990): Sense of community in the urban environment: A catalyst for participation and community development. American Journal of Community Psychology, 18(1), str. 55-81.

Chen, S. C. Y., in Webster, C. J. (2005): Homeowners associations, collective action and the costs of private governance. Housing Studies, 20(2), str. 205-220.

Choy, Y. L. (1998): Building safety issues. V: Buildings Department (ur.): Building construction in Hong Kong, str. 3-14. Hongkong, Buildings Department.

Coleman, J. (1988): Social capital in the creation of human capital. American Journal of Sociology, 94, str. 95-120.

Delovna skupina za varnost in preventivno vzdrževanje stavb (2001): Accidents related to building safety since 1990. Dostopno na: http://www.hplb.gov.hk/taskforce (sneto 3. 2. 2007).

Ellickson, R. C. (1991): Order with law: How neighbors settle disputes. London, Harvard University Press.

Elsinga, M., in Hoekstra, J. (2005): Homeownership and housing satisfaction. Journal of Housing and the Built Environment, 20(4), str. 401-424.

Elster, J. (1989): The cement of society: A study of social order. Cambridge, Cambridge University Press.

Galster, G., in Hesser, G. W. (1981): Residential satisfaction: compositional and contextual correlates. Environment and Behavior, 13(6), str. 735-758.

Ha, M., in Weber, M. J. (2009): Residential quality and satisfaction: Toward developing residential quality indexes. Family and Consumer Sciences Research Journal, 22(3), str. 296-308.

Hornburg, S. P., in Lang, R. E. (1997): What is social capital and why is it important to public policy? Prispevek je bil predstavljen na konferenci, z naslovom Annual Housing Conference of the Fannie Mae Foundation, ki je potekala v Washingtonu v Združenih državah Amerike. Tipkopis.

Lai, A. W. Y. (2003): Control on unauthorized building works in Hong Kong. V: Division of Building Science and Technology (ur.): Building design and development in Hong Kong, str. 37-57. Hongkong, City University of Hong Kong Press.

Lai, L. W. C., in Chan, P. Y .L. (2004): The formation of owners' corporations in Hong Kong's private housing estates: A probit evaluation of Mancur Olson's group theory. Property Management, 22(1), str. 55-68. 
Leung, A. Y. T., in Yiu, C. Y. (2004): A review of building conditions in Hong Kong. V: Leung, A. Y. T., in Yiu, C. Y. (ur.): Building dilapidation and rejuvenation in Hong Kong, str. 11-34. Hongkong, City University of Hong Kong and the Hong Kong Institute of Surveyors.

Liu, A. M. M. (1999): Resident satisfaction in housing estates: A Hong Kong perspective. Automation in Construction, 8(4), str. 511-524.

Long, D. A., in Perkins, D. D. (2003): Confirmatory factor analysis of the Sense of Community Index and development of a brief SCl. Journal of Community Psychology, 31, str. 279-296.

Lynn, W. R. (1999): Megacities: Sweet dreams or environmental nightmares? Environmental Science and Technology, 33(11), str. 238-240.

Mandič, S. (2006): Social capital and housing maintenance - Empirical findings from 2005 Slovenian housing survey. Dostopno na: http://enhr2006-ljubljana.uirs.si/c_papers.asp (sneto 15. 2. 2010).

Mayer, M. (2003): The onward sweep of social capital: Causes and consequences for understanding cities, communities and urban movements. International Journal of Urban and Regional Research, 27(1), str. 110-132.

Nield, S. (1990): Legal framework of deeds of mutual covenant. V: Nield, S., in Sihombing, J. (ur.): Multi-storey building management, str. 1-25. Hongkong, Hong Kong Law Journal.

Olson, M. (1965): The logic of collective action. Cambridge, MA, Harvard University Press.

Omuta, G. E. D. (2004): The quality of urban life and the perception of livability: A case study of neighbourhoods in Benin City, Nigeria. Social Indicators Research, 20(4), str. 417-440.

Ostrom, E. (1990): Governing the commons: The evolution of institutions for collective action. Cambridge, Cambridge University Press.

Pooley, J. A., Cohen, L., in Pike, L. T. (2005): Can sense of community inform social capital? The Social Science Journal, 42(1), str. 71-79.

Požarna služba (2009): Hong Kong fire services review 2008. Hongkong.

Putnam, R. (2000): Bowling alone: The collapse and revival of American community. New York, Simon and Schuster.

Saegert, S., in Winkel, G. (1998): Social capital and the revitalization of New York City's distressed inner-city housing. Housing Policy Debate, 9(1), str. 17-60.

Urad za informiranje (2005): Proper window maintenance urged. Dostopno na: http://www.news.gov.hk/en/category/ healthandcommunity/050627/html/050627en05004.htm (sneto 13. 12. 2009).

Urad za javno upravljanje (1999): Models of resident controlled housing. London.

Urad za stanovanja, načrtovanje in zemljišča (2005): Building management and maintenance - Public consultation on mandatory building inspection. Hongkong.

Urad za stavbe (1999): Monthly Digest: January 1999. Hongkong. Urad za stavbe (2003): Monthly Digest: January 2003. Hongkong. Urad za stavbe (2007): Buildings Department's enforcement policy against unauthorized building works. Hongkong.
Urad za stavbe (2008): Monthly Digest: January 2008. Hongkong. Urad za stavbe (2010): Monthly Digest: January 2010. Hongkong. Urad za varnost in urad za notranje zadeve (1998): Consultation paper on proposals to improve fire safety in private buildings. Hongkong.

Vlahov, D., in Galea, S. (2002): Urbanization, urbanicity and health. Journal of Urban Health, 79(1), str. 1-12.

Walters, M. (2002): Transaction costs of collective action in Hong Kong high rise real estate. International Journal of Social Economics, 29(4), str. 299-314.

Walters, M., in Hastings, E. M. (1998): But is fire the issue .. .? The problems of managing multiple ownership buildings in Hong Kong. Property Management, 16(4), str. 229-235.

Walters, M., in Kent, P. (2000): Institutional economics and property strata title - A survey and case study. Journal of Property Research, 17(3), str. 221-240.

Wandersman, A., in Giamartino, G. A. (1980): Community and individual difference characteristics as influences on initial participation. American Journal of Community Psychology, 8(2), str. 217-228.

Werner, I. B. (2006): The role of social capital in housing management: Pilot studies in four Sweden housing areas. Prispevek je bil predstavljen na konferenci, z naslovom EHNR International Conference, ki je potekala od 2. do 5. julija v Ljubljani v Sloveniji. Tipkopis.

Werner, I. B. (2007): Social capital in housing management: The concept as a tool for analysing problems and formulating goals for action. Prispevek je bil predstavljen na konferenci, z naslovom EHNR International Conference, ki je potekala od 25. do 28. junija v Rotterdamu na Nizozemskem. Tipkopis.

Weston, J. S. (2001): Creating and using social capital. V: Kemp, R. L. (ur.) The inner city: A handbook for renewal, str. 84-97. London, McFarland and Company.

Yip, N. M., in Forrest, R. (2002): Property owning democracies? Home owner corporations in Hong Kong. Housing Studies, 17(5), str. $703-720$.

Yiu, C. Y. (2005): Institutional arrangement and unauthorized building works in Hong Kong. Structural Survey, 23(1), str. 22-29.

Yiu, C. Y., in Yau, Y. (2005): Exemption and illegality - The dividing line for building works in Hong Kong. $C I O B(H K)$ Quarterly Journal, oktober, str. 16-19. 